Ittishal Educational Research Journal

July 2020, Vol. 1, No. 01, p. 26 - 39

http://journal.ittishal.net/index.php/ierj

DOI:10.51425/ierj.v1i1.9

\title{
The Differences Between Arabic Language Teaching for Single Rooted Foreign Speakers and Multiple Rooted Foreign Speakers
}

\author{
(A Case study in Assalam Islamic Boarding School, Indonesia and \\ An-Nile Center of Arabic Language Study for Foreigner, Cairo)
}

\author{
Alfiyatul Azizah \\ Assalaam Islamic Modern Boarding School, Sukoharjo, Indonesia \\ azizahbintiharun@gmail.com
}

\begin{abstract}
The Arabic language teaching has been developed rapidly through this modern era as a result of the world wide acceptance to study this language. Language enthusiasts as well as the scholars have noticed some development of Arabic language on several ways as well as its advancement according to the linguistic and geographic condition of learners. This study aims to understand some differences of Arabic language teaching for students who speak in single rooted language and students who speak in multiple rooted language. The single rooted language one took a sample from Assalam Islamic Boarding School where all of the student came from single rooted language, Malay language. While another one took a sample from An-Nile Center of Arabic Language Study for Foreigner, Cairo where the students came from several roots of languages, such as Malay, European, Russian, Turkish, African, and so on. In addition, this study aims to understand some difficulties and challenges the students and teachers face, and compare the percentage results of 4 language development skills between the two groups. The result of this study, based on those two institutions' Arabic teaching methods, it is concluded that the comparison result of 4 language skills shows that the Arabic teaching method for Multiple Rooted Foreign Speakers (Taken from An-Nile Arabic Language Center) is better than Arabic teaching for the single rooted language
\end{abstract}


speakers, especially on the speaking skill. In another side, we found that one of reasons why Arabic teaching method for foreigners from single rooted language speakers is weaker - is due to the tendency of language teachers to perform translation for Arabic words into their own particular language and the less of creative media invention uses which allow them to explain Arabic words with Arabic language.

Keywords. teaching method; Arabic Language, mother's language

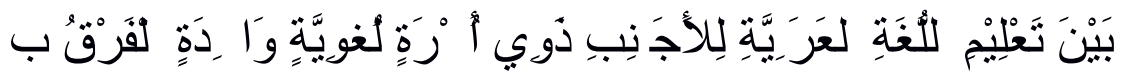

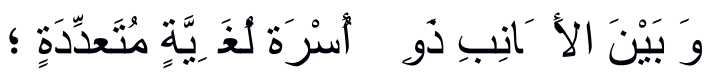

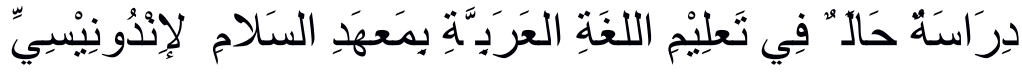

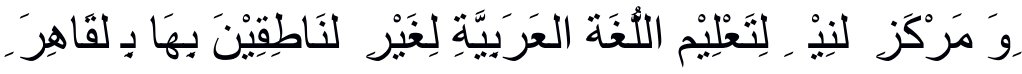

$$
\text { لفية الـ زيزة }
$$

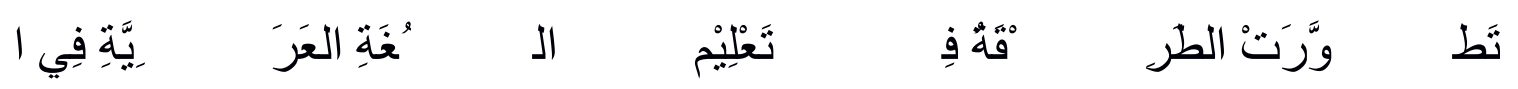

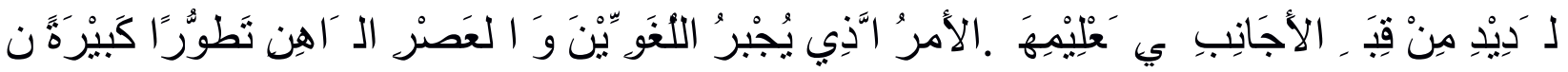

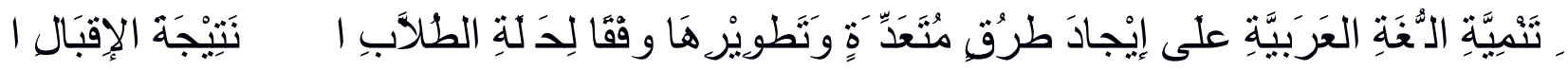

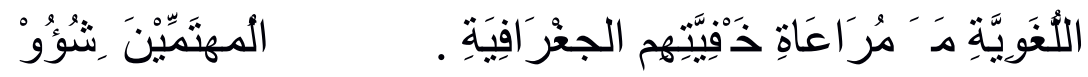

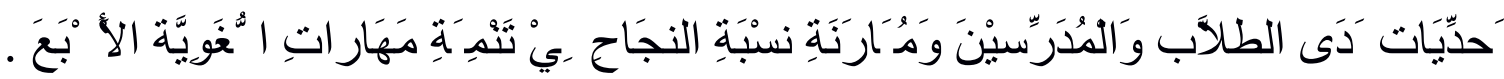

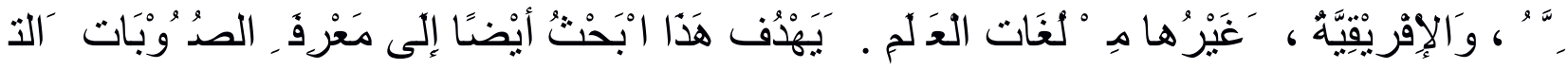

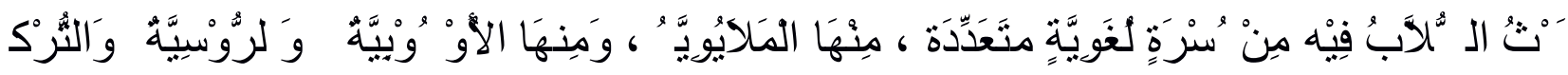

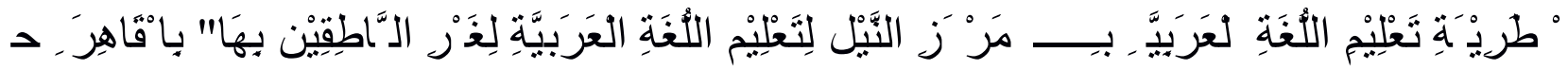




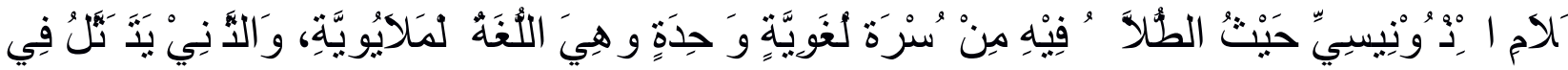

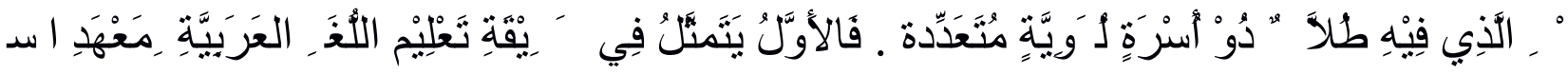

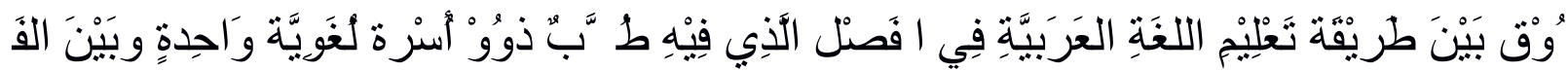

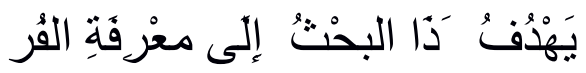

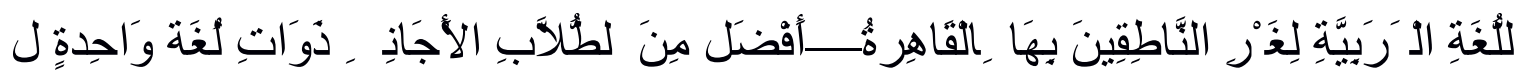

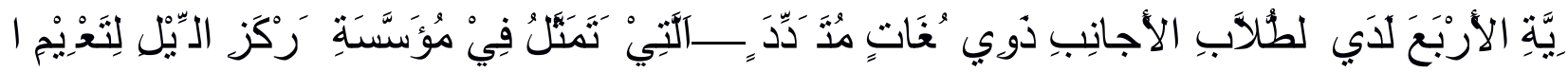

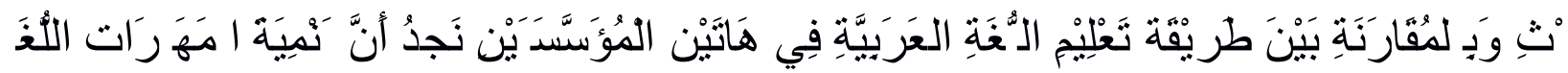

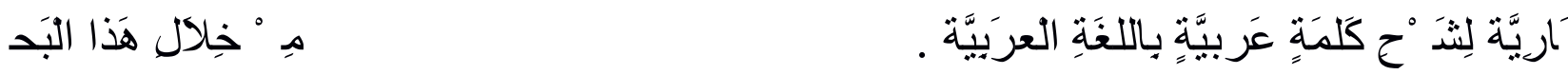

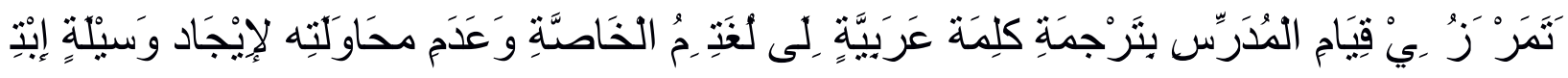

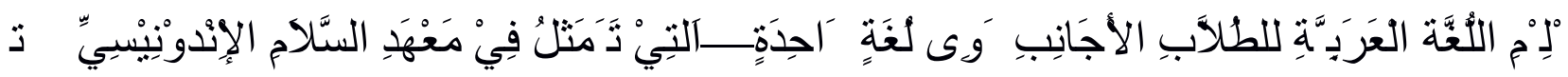

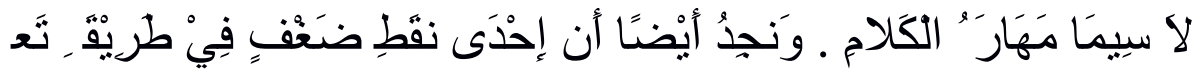

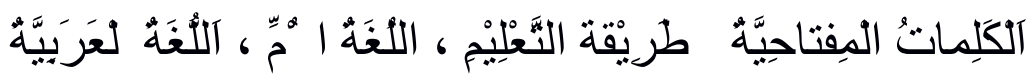




\section{قدمة}

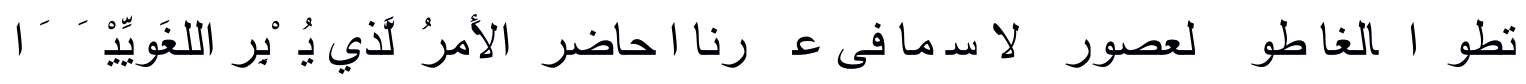

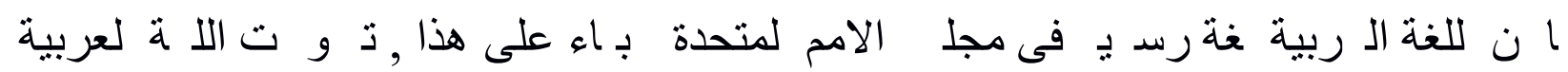

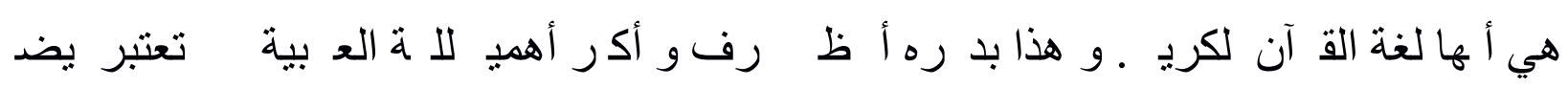

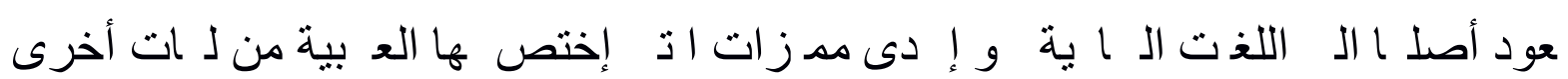

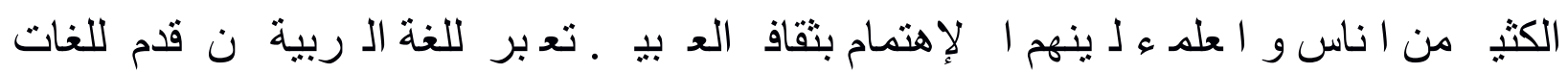

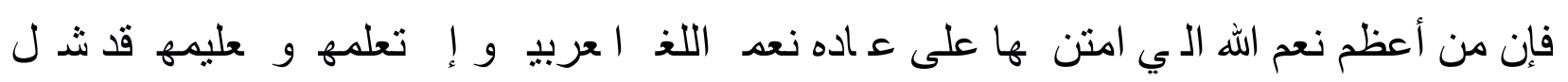

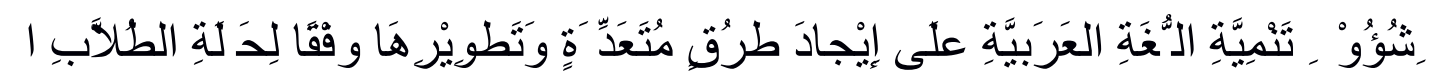

تَمَِِّنْ المهـ

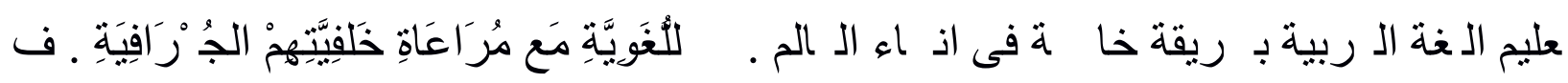

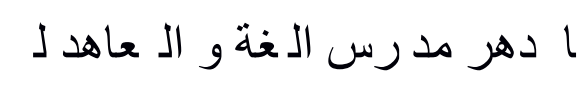

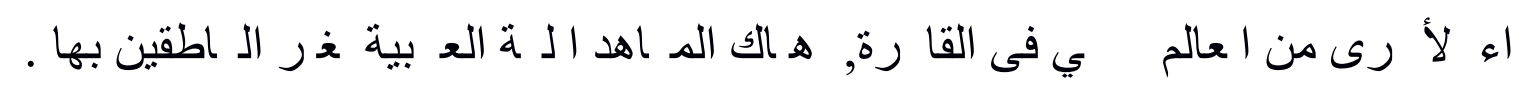

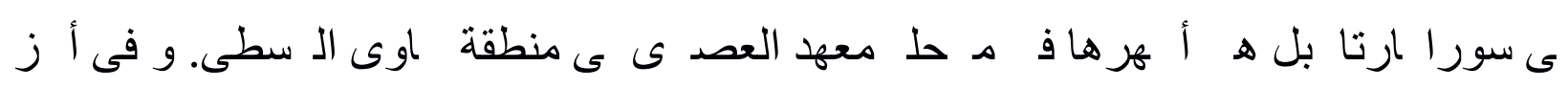

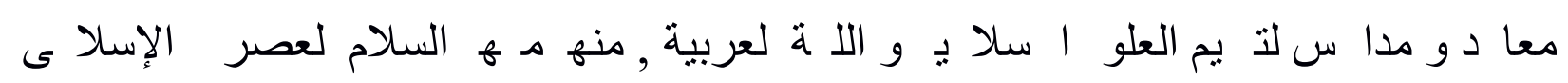
فى إندوذسيا ثنا , هذ كل

يـ يرا, ختلاف ق فتهم و منظر تربوي ما ـ كل هـ ه الددب بـ تاج الى جهد كبر طب ا.

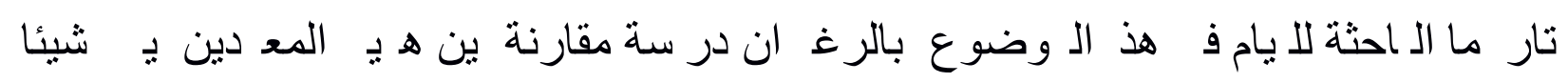
• فقا للباحث ان ك هـ الفر ق يؤدي أى ف ق فاءة ط بهم. فصدرا هذان لمعه ان مكان خ

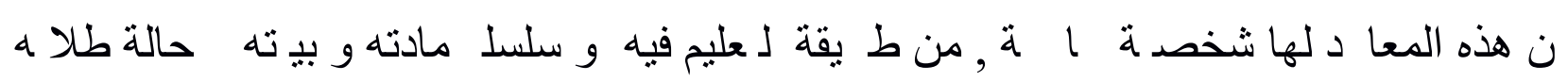
لك Ses 


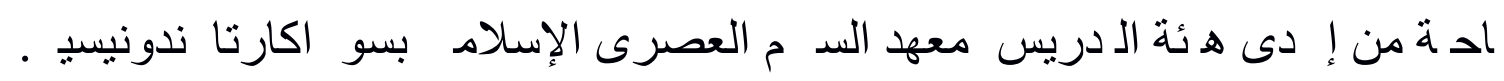

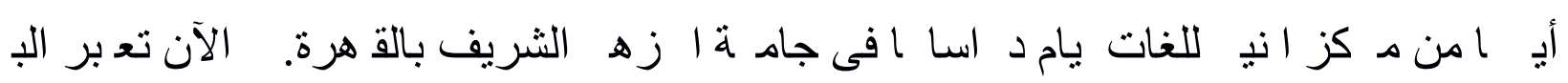

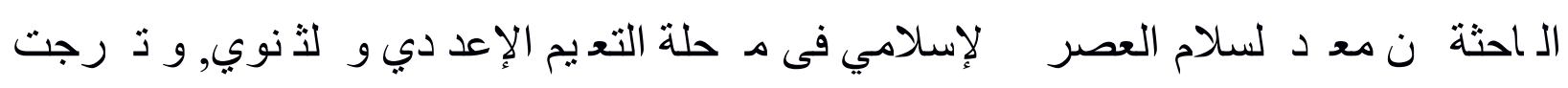

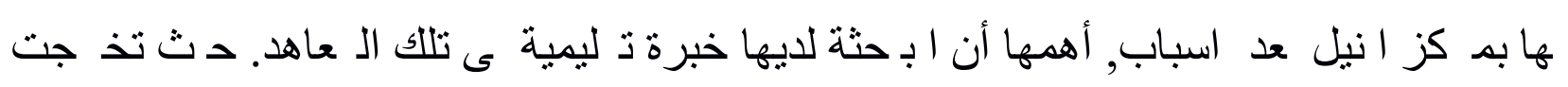

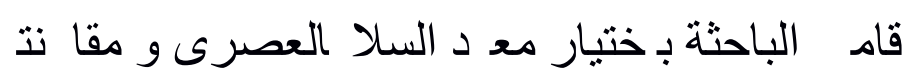

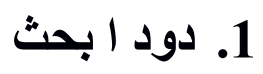

دة لجوانب، تداج إى در سات دمعاقب ومنظاف ة؛ ول ا فقد ت تحدي هذا البحث يم يلي:

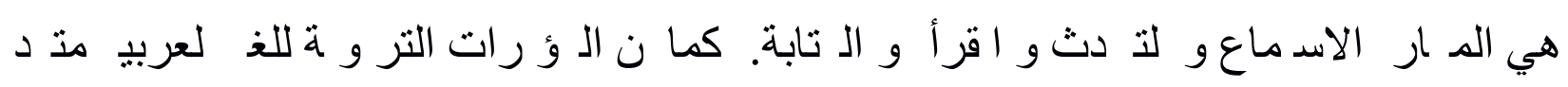

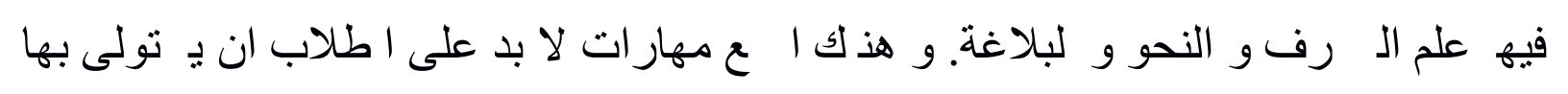

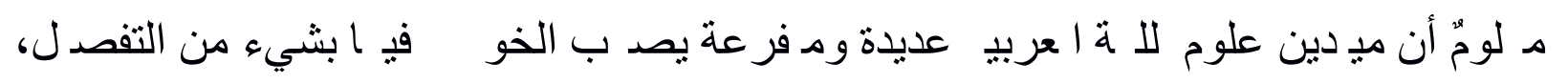

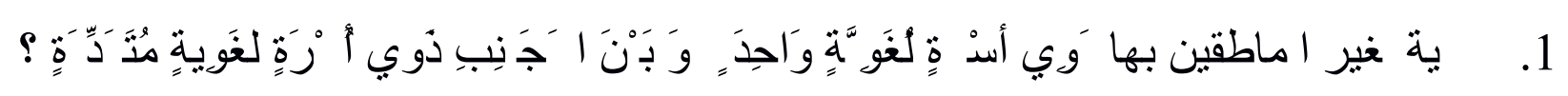

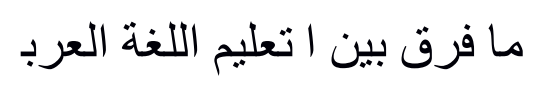

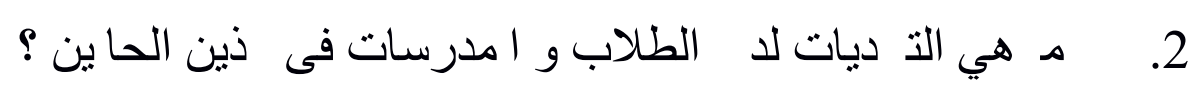

داف ابحث أه

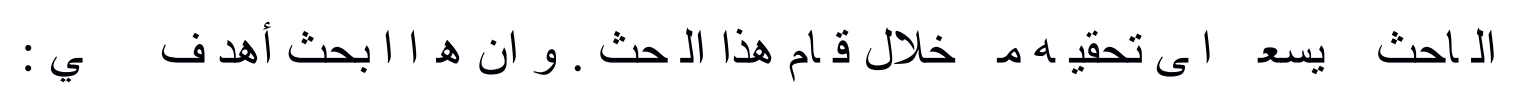

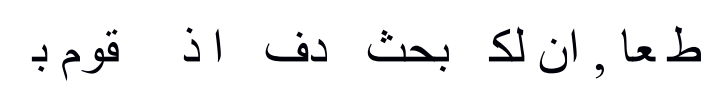

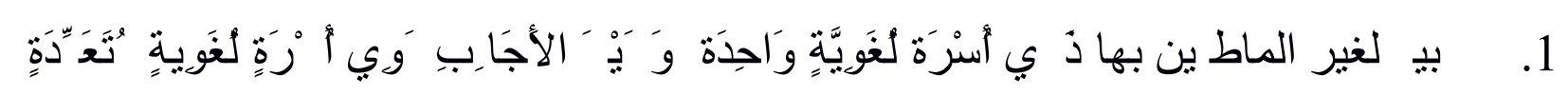

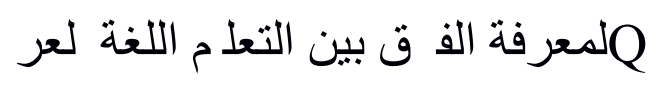

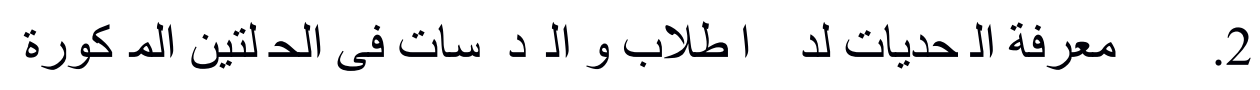




\section{ريقة لبحث طر}

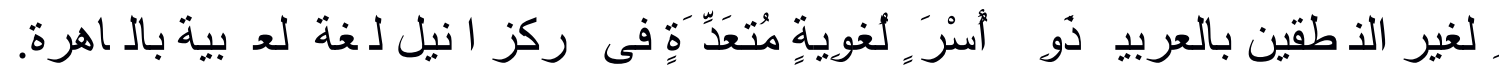

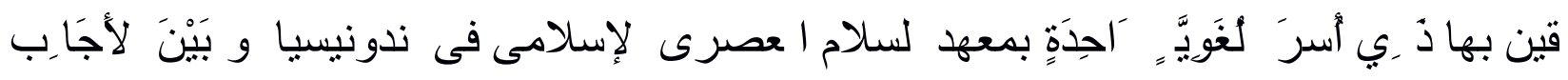

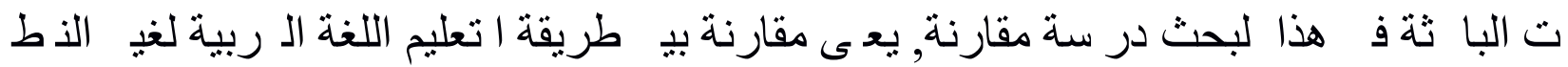

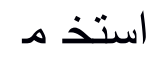

أ أمت الـ احثة مقا نة بـ ذه الب انات الأ ية :

1. 1 - مالة الطلاب بها

2. 2. مادة الت است دمها

3. ريقة التعليم فيها

\section{حليل الب انات تح}

1

a المعومات العا ماتة

تأسس عهد ال لام العصر الإسلاه فى شه أغد س 198219يع. فيه 5

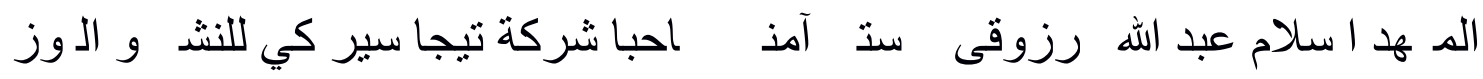

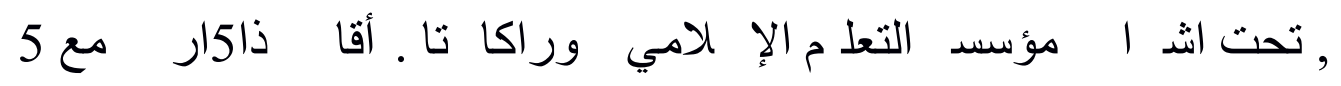

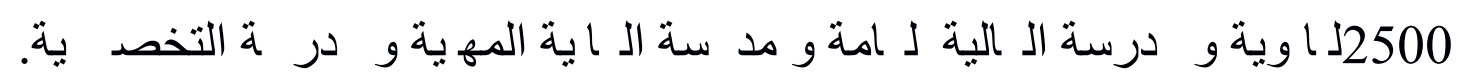

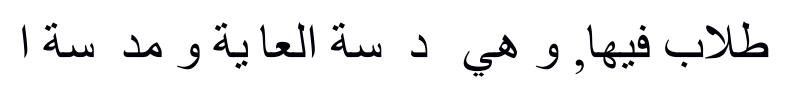


ز رة سو وي ي و جزيرة اب او غر ذلك ن جزر نشر ف دولة ندونيدا.

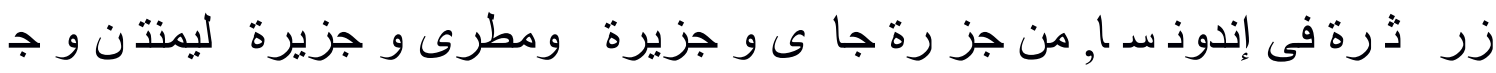
جاء الطلاب للتع م ى هذا الد هر من

فيتع م الطلاب فيها عل ما ك يـ ة. بـ نما هم عيشون طو ايامه فى هذ الـ عهد.

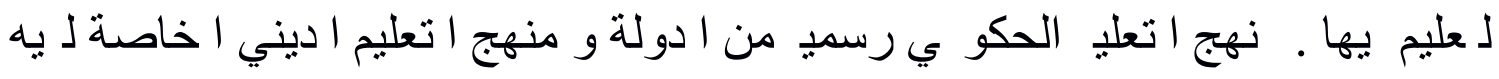

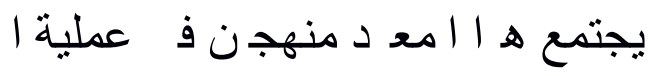

تعلم اطلاب ء هذه للا ة ى فصوله ـو فى كل اسدوع تعلم الـ لاب حو لى 8

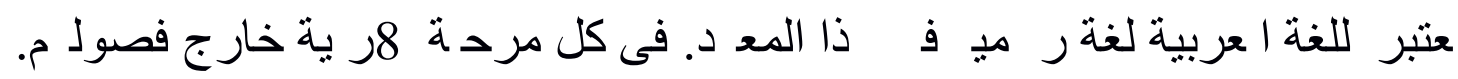

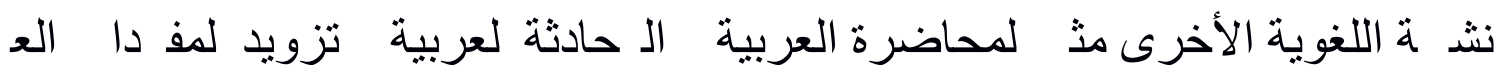

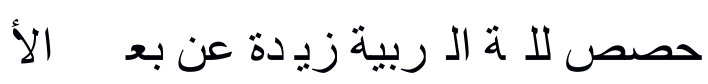

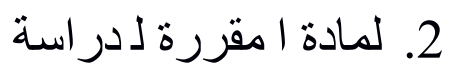

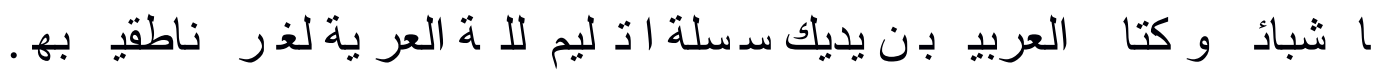

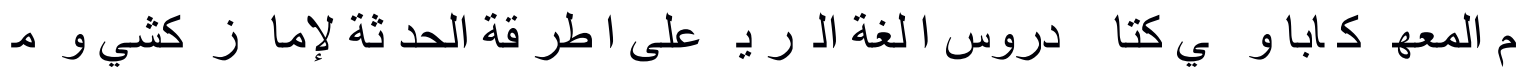

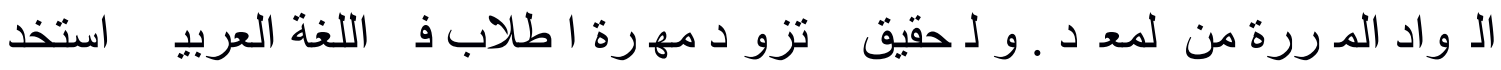

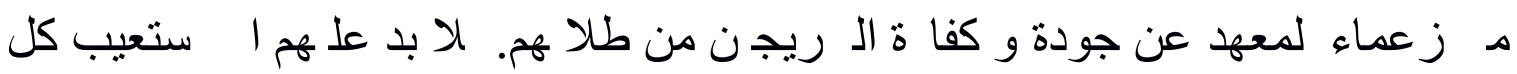
ق ق قام تقر ر

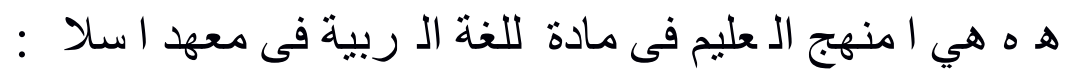




\begin{tabular}{|c|c|c|c|c|c|c|c|c|}
\hline تصف الـ صصى & $\begin{array}{l}6 \text { ف } \\
6\end{array}$ & ف 5 & ف 4 & $\begin{array}{l}3 \dot{ } \\
3\end{array}$ & $\begin{array}{l}2 \text { ف } \\
2\end{array}$ & $\begin{array}{l}1 \\
1\end{array}$ & لمادة & \\
\hline 8 & & & & 2 & 4 & 8 & رو الغة & للغة ربية \\
\hline 4 & 2 & 2 & 2 & 2 & 2 & & لنحو & \\
\hline 2 & 1 & 1 & 1 & 2 & 2 & & لصرف & \\
\hline 2 & & 1 & 1 & 1 & 1 & 1 & الإنشاء & \\
\hline 2 & 1 & 2 & 2 & 1 & 1 & 1 & لمطا عة ألمر & \\
\hline 2 & & & & & & 1 & فو ظات & \\
\hline
\end{tabular}

. الـ ريقة الـ عليم في ا .

سد خدم لـ علم فى هـ I المعه طر التعل م امت ددة , نها : 
- ريدة عى المعل بشكل مباشر بينم اطلاب نتاين قط دون سد هسة او شركة فها.

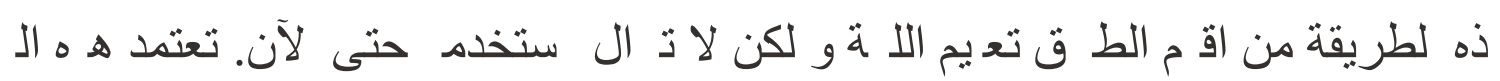

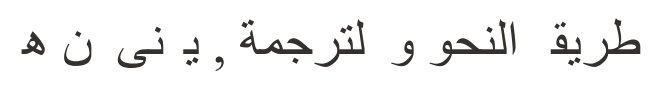

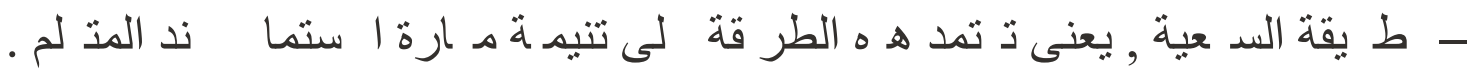

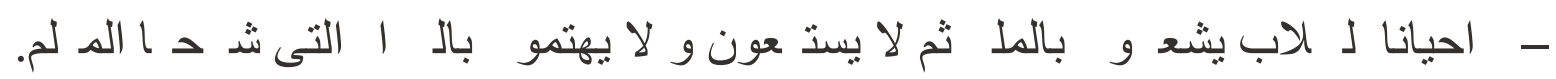

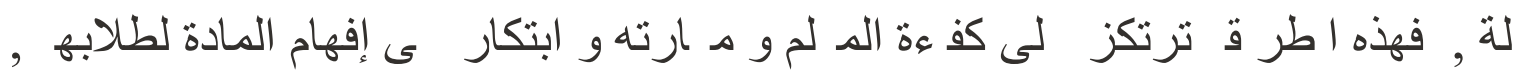
طريق الثر و ا سئ

\section{2 مركز ا نيل للفات - ج هورية مصر ا عربي

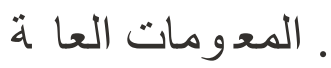

س مـ كز الني لتعل م اللغ العر ية سدة 199819 الد ار بين لطلب و الـ علم

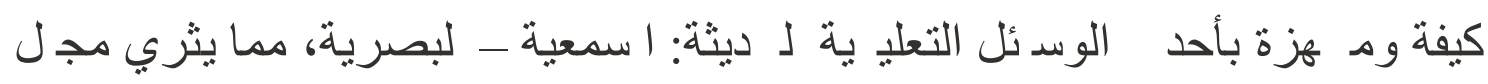

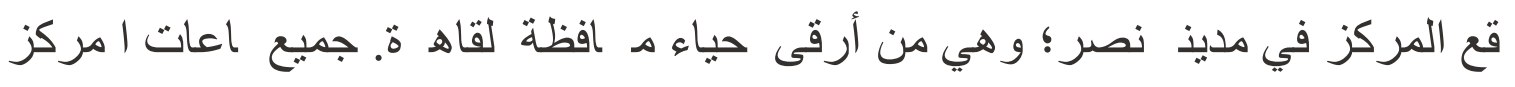

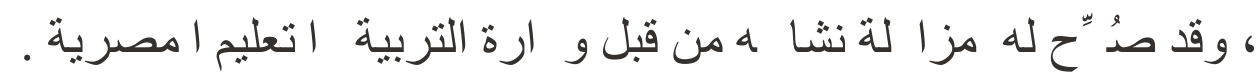

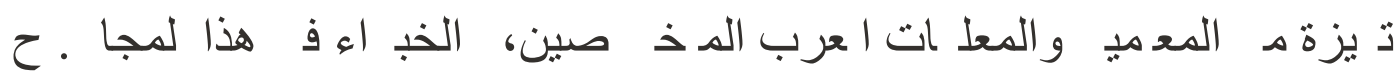
ربة لأجاذ ؛ ذ رالما يو رهمن احة ورف هية طلا هوطا بات ؛ كم يوجد به نخبة هـ

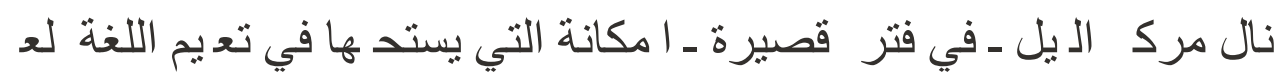

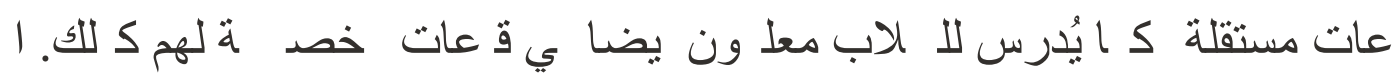

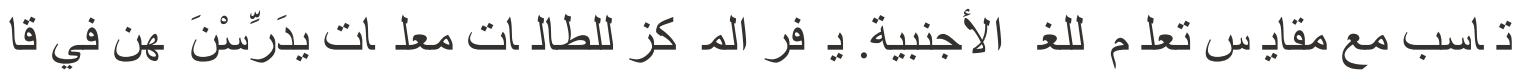

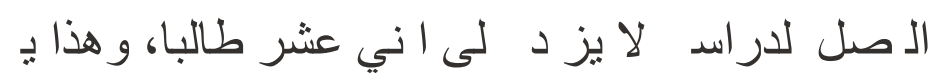


قرة العالم. حدث يجبر الـ علمين بـ اطريق حدثة مناسبة و مد بو لدى ط بهم.

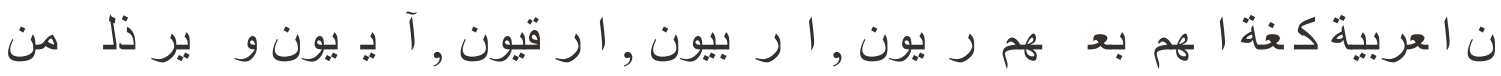
يتعط ال لاب فى ذ المرك من د ل متف قة . اكثرهم لا ينطق لأفلا , اشريط, زيادة لمردات و الوراعد, صو اعربو غر ذلك

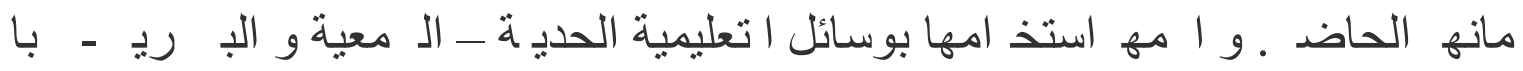
أن هذ لمركز بـ ت دم وسائ التعليم لعصرية الذى ينا ب مع ح ال طلابه كأبنا ز ز

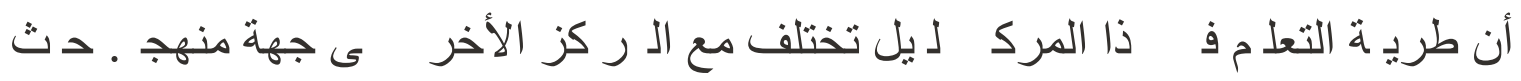

لـ ات تقسيم لف ول ال إثى عثد مسدوى هي لإبتدا ع و ا منوسط و المت دم. اقام الم ك النيل ف كل المستو يهدف لتعليم ى مهار ت للغوية لأربع بثلاثة كب

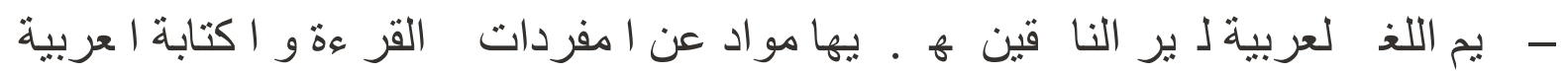
الكتاب لأساسي لـ - ار لـعيم الغة لع بية غير لـ اطقن بها ـ يها واد عن لم الـ رف و اقواعد اعربية لكتاب ا مخت

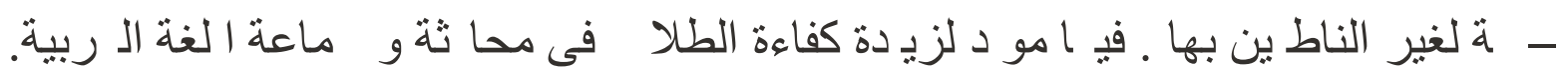
الكتاب انكلم تعليم الغة الـ رب 
علم ال لاب ل ذ ذه الم اد 4040ر الطلاب د استه لكل لـ ستوى حو لى 3 ب مادة لمحادث العربة زيادة هم لت قية مهر رة تكل هم بأ لوب عر ية صيحة. و يستغ اعة ا بو عيا ـ بجا3 سابيع و ينتهى بإ نر ك فى الإ تحان لـ لهائي .

ف ظ لمفردا و تك ينها فى جما مفيد تى فه الم اطب على ايقصد . به الممتا ة. علم بأن اللغة العربية لي ت لغة امه , طب اليحتاج الى جهد بير ف ت تد

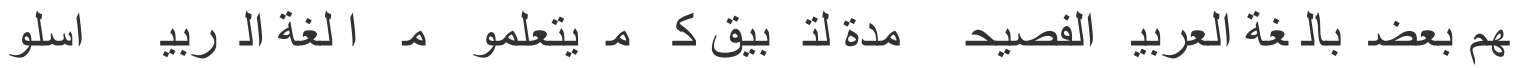

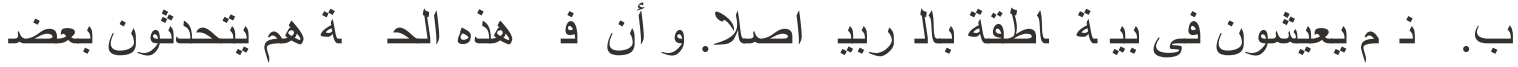
صبحت اماة ا محادثة رصة غالة و مـ تعة دى الطلا

بح ن تعارف يـ هما يسهل ال علم لإخيار لطر قة اخاصة هم و طبيق ا الي م. ما لة قوية يت دث عضهابـ ض ن الصعو ة قي امادة تى عن احوا هم لشخصية من خصية مرك لنيللغات يوجد في نخبة دميزة د الم لمين و الطلاب ـ حي بينه

. طر قة التع يم في ا . ا.

ال طلاب م كبذء ز انهم ا حاضد ـ اهمها استخدام ا وسائل التعل مية ا حديث جهة نهجه. يث أن ذا الم كز يسدخد وسائ الت ليم العصد ية. الذ يناسد مع اح

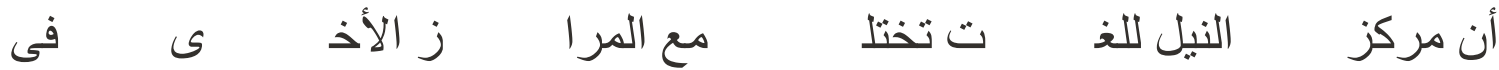

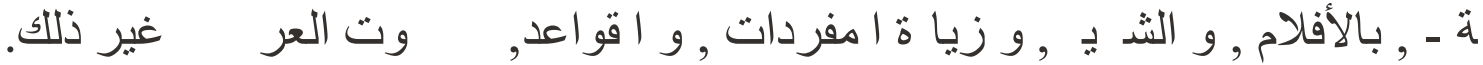
و الـ تقد ة - الـ معي البصريد 


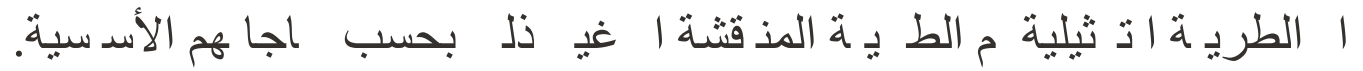

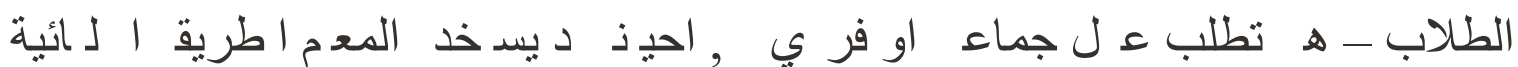
تخدم لمعلم ط ق مخلفة على حس موضوع ا مادة و ست ى الطلاب و مدى مشا كة

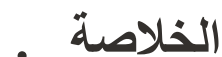

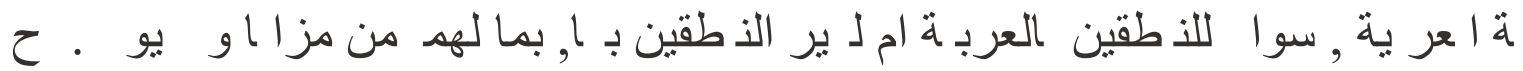
بأ ال عهد لسلام الع رى و مر ز النيل لغات لهم دور كير فى ت وير أ اليب عليم الغ تضح مـ لال الرا و فيما يلي برز الذ صة و التوصيات لـ ذه الدر سة امتو ضعة

\begin{tabular}{|c|c|c|c|}
\hline كز الـ يل لا ات & لام الل صرى الإ لامي & وضوع لبحث & ل ل ل لرقم \\
\hline 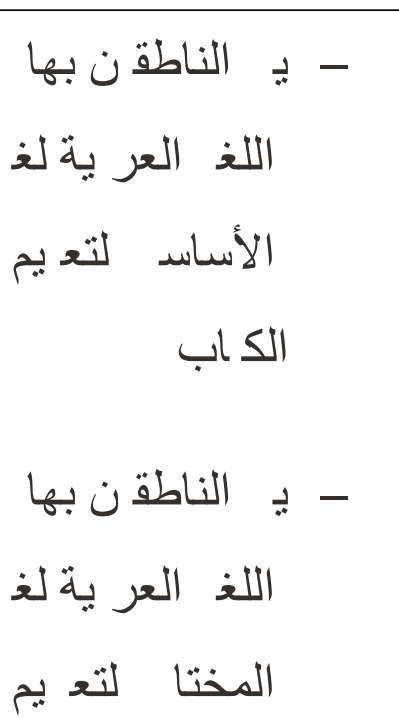 & 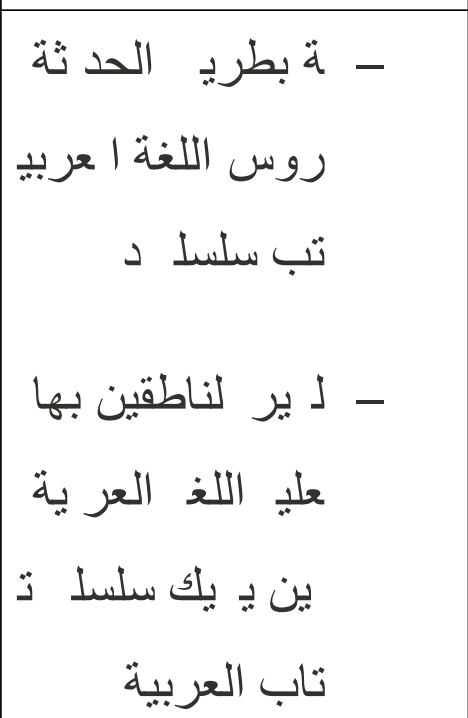 & قررات الـ راسية & 1 \\
\hline
\end{tabular}




\begin{tabular}{|c|c|c|c|}
\hline 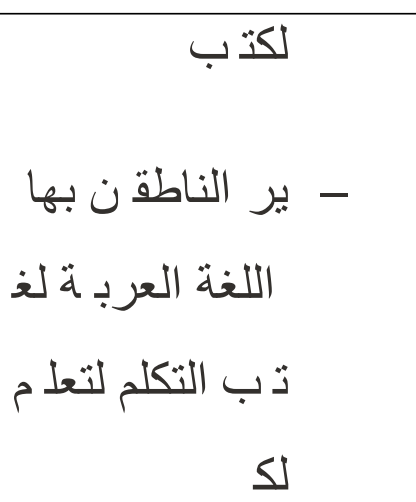 & & & \\
\hline يثة, تدمة د د داصرة & ديثة, ت دمة و عاصرة & لوسائل لتعليم & 2 \\
\hline 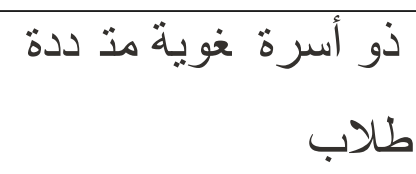 & طب ذ أسرة لغويـ و حدة & خلفية لطلاب & 3 \\
\hline خريج كلأة ف اللغ الع بية & 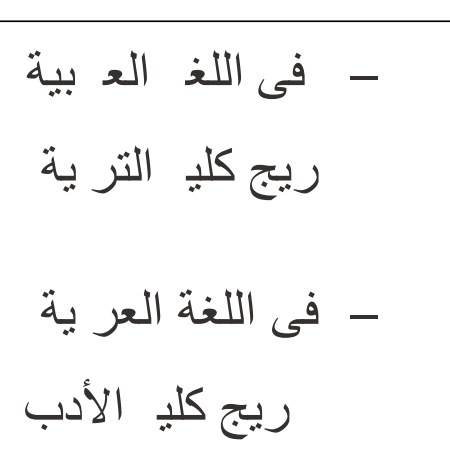 & لخلفية العلمية للمعلم & 4 \\
\hline & 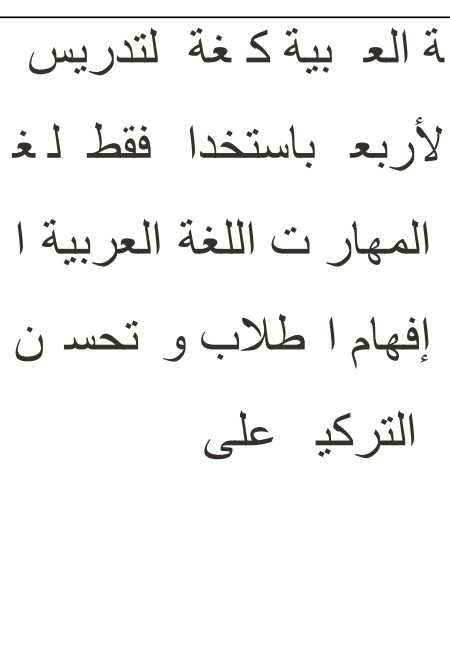 & 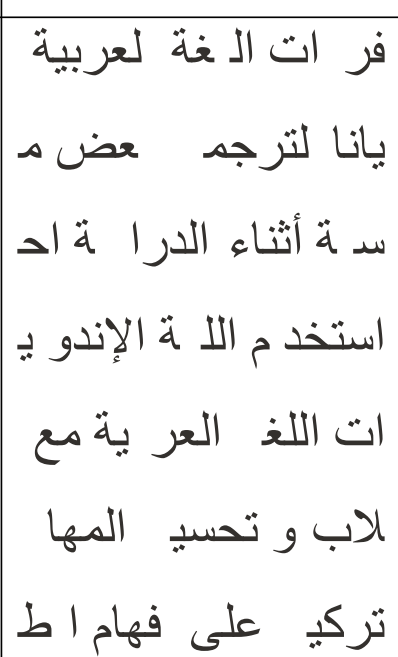 & لو ربة \\
\hline
\end{tabular}




\begin{tabular}{|c|c|c|c|}
\hline & & ال & \\
\hline ماسة ديدة & وع من ا حد سة & 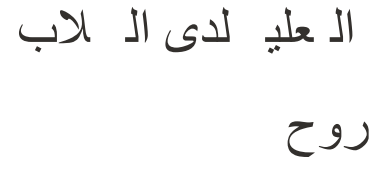 & 6 \\
\hline 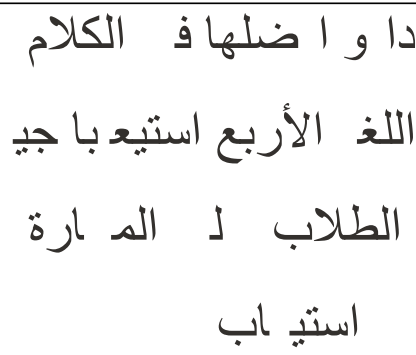 & فهم لد هارة لـ لام و ال تنابة & ع لقب الموا الـ راسية & 7 \\
\hline
\end{tabular}

